\title{
Weather-driven deterioration processes affecting the performance of embankment slopes
}

\author{
ROSS A. STIRLING*, DAVID G. TOLL $\$$, STEPHANIE GLENDINNING $\dagger$, PETER R. HELM†, \\ ANIL YILDIZ†, PAUL N. HUGHES $\$$ and JONATHAN D. ASQUITH§
}

\begin{abstract}
Deterioration of earthworks and the resultant implications for serviceability and increased occurrence of failures have a significant negative impact on transport networks both in the UK and internationally. There is evidence in the field that deterioration processes are occurring over the life of an asset, comprising cracking and loss of suction. These are weather-driven processes that occur in the absence of increased mechanical loads and can lead to failure many years after construction. To demonstrate the progressive loss in mechanical performance of clay fill due to a purely environmentally driven deterioration process, a programme of unsaturated triaxial testing was carried out. A new mechanism of soil deterioration driven by cyclic wetting and drying is proposed, based on an extensive laboratory and field experimental programme. The underlying cause for this is the micro-structural changes to the soil fabric leading to loss of suction generation capacity. In addition, cracking leads to changes in hydraulic conductivity and the movement of water into and out of the soil. The implications for slope stability assessment include the need for changeability of soil parameters and of the ground model, with changes occurring both seasonally and gradually over time.
\end{abstract}

KEYWORDS: fabric/structure of soils; field instrumentation; laboratory tests; partial saturation; slopes

\section{INTRODUCTION}

The deterioration and resultant failures of infrastructure slopes have a significant negative impact on transport networks both in the UK and internationally. For example, in 2015 there were 143 earthworks failures on the UK rail network, which equates to more than two per week. The costs are high: the annual expenditure on routine maintenance for earthworks on the railway network was $£ 154$ million in 2016/2017 and £111 million in 2017/2018 (Network Rail, 2017, 2018), with emergency repairs costing ten times planned works, which in turn cost ten times more than maintenance (Glendinning et al., 2009). There is a need to manage the performance of assets and therefore a need to better understand the underlying deterioration processes that may ultimately lead towards failure, in order to improve the way in which assets are monitored and managed to reduce the risk of unanticipated failure and reduce both the economic and the social impacts of the disruption this causes.

There is anecdotal (Nugent, 2012; BBC, 2014, 2017) and systematic (Ridley et al., 2004) evidence that suggests extreme weather events contribute to the occurrence of failure. Many researchers have investigated the processes that lead to failure, including construction-induced pore-water pressure dissipation in cut slopes, seasonal cycling of pore pressures due to weather and other mechanisms, such as vegetation removal,

Manuscript received 15 February 2019; revised manuscript accepted 20 April 2020. Published online ahead of print 26 May 2020.

Discussion on this paper closes on 1 March 2022, for further details see p. ii.

Published with permission by the ICE under the CC-BY 4.0 license. (http://creativecommons.org/licenses/by/4.0/)

* School of Engineering, Newcastle University, Newcastle Upon Tyne, UK (Orcid:0000-0002-0069-6621).

$\uparrow$ School of Engineering, Newcastle University, Newcastle Upon Tyne, UK.

$\$$ Department of Engineering, Durham University, Durham, UK. § Formerly Department of Engineering, Durham University, Durham, UK. all leading to deterioration, usually taking the form of plastic shear strain-softening, numerically modelled in both cut slopes (Potts et al., 1997; Kovacevic et al., 2007) and embankments (Nyambayo et al., 2004; Rouainia et al., 2009; Kovacevic et al., 2013). Others have looked at the effects of seasonal cracking in the field (Anderson et al., 1982) and down-slope ratcheting in centrifuge modelling (Take \& Bolton, 2011). The influence of vegetation growth and removal on the deterioration of cut slope stability has also been numerically modelled (Tsiampousi et al., 2017). Hudacsek et al. (2009) also undertook centrifuge testing on an embankment model subject to seasonal weather cycles; however, this work did not demonstrate the type of seasonal ratcheting seen by Take \& Bolton (2011) or softening (observed in the numerical modelling summarised above). They attributed this in part to the different stress histories of the respective models. At present, there has been no work to tie these phenomena together, despite the evidence that cracking influences the rate at which water enters and leaves the slope and cracks provide sites for stress concentration that can lead to local movement and then progressive failure as the soil moves towards a residual strength (Skempton, 1964, 1985; Lupini et al., 1981; Mesri \& Cepeda-Diaz, 1986).

This work proposes a new unified process of weatherdriven deterioration, building on this evidence from the literature. A rigorous laboratory and field study has been used to provide the supporting evidence for a link between wetting and drying processes and micro-scale changes in fabric, which in turn lead to reduced strength, and alterations to soil-water retention behaviour. It also demonstrates how these changes manifest in the field at the macro-scale, leading to deterioration of infrastructure slopes; and indicates how this form of deterioration can lead to progressive failure and how the risk of failure may be increased in the future.

The work described in this paper provides new understanding of weather-driven deterioration, which can underpin the development of the new asset management approaches that are required to reduce the risk of failure with significant reduction in future social and economic costs. 


\section{STRENGTH REDUCTION}

To investigate the progressive loss in mechanical performance of clay fill due to wetting and drying processes, a programme of unsaturated triaxial testing at constant water content was performed. The material studied in this work is a sandy clay derived from Durham Lower Boulder Clay (a glacial till referred to as Nafferton soil herein). This soil was used in the construction of the Bionics full-scale research embankment (Hughes et al., 2009; Glendinning et al., 2014), located at Nafferton in the north east of England, near Newcastle upon Tyne. The prepared material comprised 30\% sand, $35 \%$ silt and $35 \%$ clay, with a liquid limit of $43.3 \%$ and plastic limit of $23 \cdot 7 \%$, resulting in a plasticity index of $19 \cdot 6$. The particle density was $2.66 \mathrm{Mg} / \mathrm{m}^{3}$. Air-dried soil that passed a $2.8 \mathrm{~mm}$ sieve was mixed with water to achieve $22 \%$ gravimetric water content (wet of optimum (15.4\%)) before being left to equalise for at least $24 \mathrm{~h}$. Specimens were compacted by drop hammer in a split mould measuring $100 \mathrm{~mm}$ internal diameter by $200 \mathrm{~mm}$ tall. Six layers with 27 blows per layer using the $2.5 \mathrm{~kg}$ tamper with a $300 \mathrm{~mm}$ drop were used (equivalent to Proctor compaction). The dry density achieved was $1.65 \mathrm{Mg} / \mathrm{m}^{3}$ - which is comparable with the field density achieved in the experimental embankment. The degree of saturation after compaction at $22 \%$ gravimetric water content would be equivalent to $95 \%$ (Table 1 shows a range of 93-96\%). After drying to $15 \%$, the degree of saturation would reduce to $76 \%$. On rewetting back to $22 \%$ water content, the degree of saturation increased to $92 \%$ after one cycle of drying and wetting, and between 97 and $100 \%$ after subsequent cycles of drying and wetting (as seen in Table 1).

Samples were subjected to varying numbers of dryingwetting cycles in which they were dried to a water content of $15 \%$ and then wetted back to the initial water content of $22 \%_{-1.22 \%}^{+1.31 \%}$. The dry-wet cycling was performed outside the triaxial cells by wetting inside a sealed chamber at high relative humidity and air drying as described by Mendes \&
Toll (2016). Samples were then placed inside a double cell triaxial apparatus and subjected to constant water content compression and subsequent shearing, with measurements of suction (negative pore water pressure) using high-suction tensiometers with a capacity of $1500 \mathrm{kPa}$ (Toll et al., 2013). Testing was carried out at atmospheric pressure (not using the axis translation technique) so the suctions measured are matric suctions. In most cases, at these degrees of saturation, the pore water pressures were positive after the application of the confining stress.

Testing was carried out using a multi-stage procedure at different confining pressures $(25,50$ and $100 \mathrm{kPa})$ for seven specimens, while three specimens (1,18 and 19) were tested using a single-stage procedure (see Table 1). Multistage testing was used due to the long times necessary for preparing specimens that were subjected to up to six drying and wetting cycles. There were concerns that variability between specimens could affect the results, so testing at three stress levels on the same specimen was seen as the best option. While it is recognised that peak strengths measured in subsequent stages can be affected by the degree of straining to which the specimen has previously been subjected, it was felt this would not be as important in compacted soils as it might be for natural intact specimens (with chemical bonds that would be broken down by straining). The three tests carried out as a single stage are identified in Fig. 1. In all multistage tests, the same sequence of stages was followed $(25 \mathrm{kPa}, 50 \mathrm{kPa}$ and $100 \mathrm{kPa}$ ). Therefore, the data for all tests at $25 \mathrm{kPa}$ are for first-stage tests, and would not be affected by previous shearing. Tests at $50 \mathrm{kPa}$ and $100 \mathrm{kPa}$ were carried out after previous stages of shearing, and therefore might be expected to be affected in the same way. Therefore, the trends with the number of cycles would be consistent, as is seen in Fig. 1.

The decision to end one stage and move to the next was based on continual monitoring of the $q / p^{\prime}$ ratio. When a peak in the $q / p^{\prime}$ ratio was observed, this was taken to indicate that the stage had reached the failure envelope, before progressing

Table 1. Test details for constant water content triaxial tests

\begin{tabular}{|c|c|c|c|c|c|c|c|c|}
\hline $\begin{array}{l}\text { No. of dry/ } \\
\text { wet cycles }\end{array}$ & Sample & $\begin{array}{l}\text { Confining } \\
\text { stress: } \mathrm{kPa}\end{array}$ & $\begin{array}{l}\text { Gravimetric } \\
\text { water } \\
\text { content: } \%\end{array}$ & $\begin{array}{c}\text { Degree of } \\
\text { saturation, } \\
S_{\mathrm{r}}\end{array}$ & $\begin{array}{l}\text { Initial mean } \\
\text { effective } \\
\text { stress, } \\
\left(p-u_{\mathrm{w}}\right): \mathrm{kPa}\end{array}$ & $\begin{array}{c}\text { Initial } \\
\text { pore water } \\
\text { pressure, } \\
u_{0}: \mathrm{kPa}\end{array}$ & $\begin{array}{c}\text { Mean } \\
\text { effective stress } \\
\text { at failure, } \\
\left(p-u_{\mathrm{w}}\right): \mathrm{kPa}\end{array}$ & $\begin{array}{c}\text { Deviator } \\
\text { stress at } \\
\text { failure, } \\
q: \mathrm{kPa}\end{array}$ \\
\hline 0 (as compacted) & 1 & 25 & $21 \cdot 1$ & 0.93 & 30 & -5 & 36 & 64 \\
\hline 0 (as compacted) & 2 & 25 & $21 \cdot 1$ & 0.96 & 41 & -16 & 37 & 66 \\
\hline 0 (as compacted) & 2 & 50 & $20 \cdot 8$ & 0.99 & 48 & 2 & 58 & 87 \\
\hline 0 (as compacted) & 2 & 100 & $20 \cdot 8$ & $1 \cdot 00$ & 60 & 40 & 67 & 99 \\
\hline 1 & 5 & 25 & $21 \cdot 0$ & 0.92 & 16 & 9 & 15 & 34 \\
\hline 1 & 5 & 50 & $21 \cdot 0$ & 0.93 & 13 & 37 & 12 & 31 \\
\hline 1 & 5 & 100 & $21 \cdot 0$ & 0.95 & 15 & 85 & 11 & 35 \\
\hline 1 & 18 & 50 & $21 \cdot 0$ & 0.99 & 22 & 28 & 18 & 42 \\
\hline 1 & 19 & 100 & $22 \cdot 0$ & 0.97 & 10 & 90 & 5 & 22 \\
\hline 2 & 11 & 25 & $23 \cdot 3$ & $1 \cdot 00$ & 4 & 21 & 3 & 8 \\
\hline 2 & 11 & 50 & $23 \cdot 3$ & $1 \cdot 00$ & 4 & 46 & 3 & 13 \\
\hline 2 & 11 & 100 & $23 \cdot 3$ & $1 \cdot 00$ & 1 & 99 & 0 & 8 \\
\hline 3 & 6 & 25 & $21 \cdot 0$ & 0.97 & 8 & 17 & 4 & 14 \\
\hline 3 & 6 & 50 & $21 \cdot 0$ & 0.98 & 11 & 39 & 8 & 18 \\
\hline 3 & 6 & 100 & $21 \cdot 0$ & 0.99 & 15 & 85 & 13 & 32 \\
\hline 4 & 15 & 25 & $22 \cdot 6$ & 0.97 & 4 & 21 & 2 & 9 \\
\hline 4 & 15 & 50 & $22 \cdot 6$ & 0.99 & 4 & 45 & 4 & 16 \\
\hline 4 & 15 & 100 & $21 \cdot 6$ & $1 \cdot 00$ & 5 & 95 & 5 & 19 \\
\hline 5 & 13 & 25 & $21 \cdot 7$ & 0.99 & 3 & 22 & 3 & 15 \\
\hline 5 & 13 & 50 & $21 \cdot 7$ & 0.99 & 3 & 47 & 1 & 17 \\
\hline 5 & 13 & 100 & $21 \cdot 7$ & 0.99 & 5 & 95 & 5 & 28 \\
\hline 6 & 9 & 25 & $23 \cdot 2$ & $1 \cdot 00$ & 6 & 19 & 6 & 13 \\
\hline 6 & 9 & 50 & $23 \cdot 2$ & $1 \cdot 00$ & 7 & 43 & 7 & 14 \\
\hline 6 & 9 & 100 & $23 \cdot 2$ & $1 \cdot 00$ & 9 & 91 & 9 & 14 \\
\hline
\end{tabular}




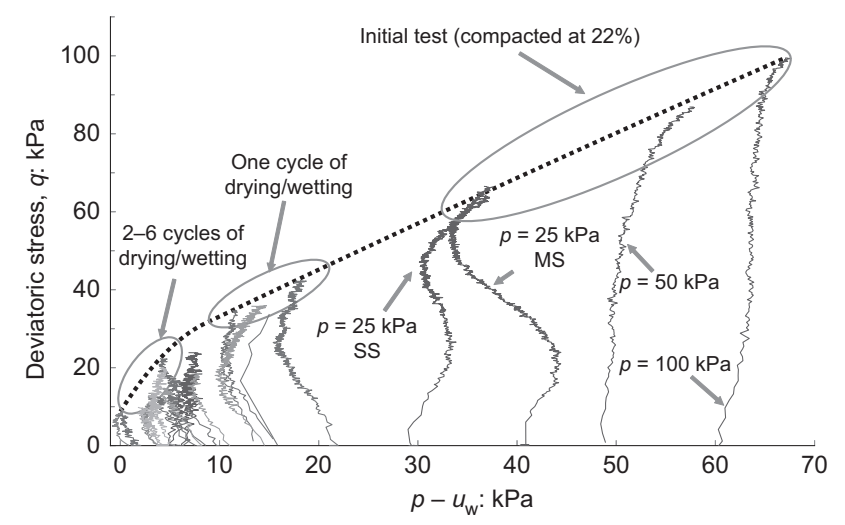

Fig. 1. Triaxial test results on unsaturated specimens subjected to cycles of drying and wetting

to the next stage. All samples were at or very near full saturation $\left(S_{\mathrm{r}}>97 \%\right)$ at the beginning of the test.

For tests at high degrees of saturation $(>90 \%)$, the results can be interpreted using a simple 'Bishop stress' approach, where Bishop's $\chi$ factor (Bishop, 1959) is taken as equal to the degree of saturation (as first used by Schrefler (1984) and justified as average soil skeleton stress by Jommi (2000)).

$$
p^{*}=p-\left[S_{\mathrm{r}} u_{\mathrm{w}}+\left(1-S_{\mathrm{r}}\right) u_{\mathrm{a}}\right]
$$

where $p^{*}$ is the mean 'Bishop stress'; $p$ is the mean total stress; $S_{\mathrm{r}}$ is the degree of saturation; $u_{\mathrm{w}}$ is pore water pressure and $u_{\mathrm{a}}$ is pore air pressure.

In this work the high degree of saturation $\left(S_{\mathrm{r}} \approx 1\right)$ in the samples leads to $u_{\mathrm{a}}$ being negligible and the resultant equation being applied

$$
p^{*}=p-u_{\mathrm{w}}
$$

Figure 1 shows the stress paths in terms of mean Bishop stress, $p^{*}$ plotted against deviatoric stress, $q$. The figure shows the deviatoric stresses at failure for the initial 'as compacted' specimens were 60-100 kPa (equivalent to shear strengths of $30-50 \mathrm{kPa}$ ), for the range of confining stresses investigated. After one cycle of drying (to $15 \%$ water content) and wetting (back to $22 \%$ ), the deviator stresses reduced to $30-45 \mathrm{kPa}$ (equivalent to shear strengths of $15-23 \mathrm{kPa}$ ). After two or more cycles of drying and wetting, the deviator stresses reduced below $30 \mathrm{kPa}$ (equivalent to shear strengths of less than $15 \mathrm{kPa}$ ).

The data have been plotted to show the decrease in deviatoric stress, $q$, for each of the three confining stresses $(25,50$ and $100 \mathrm{kPa})$ in Fig. 2. This shows a 60 to $80 \%$ shear

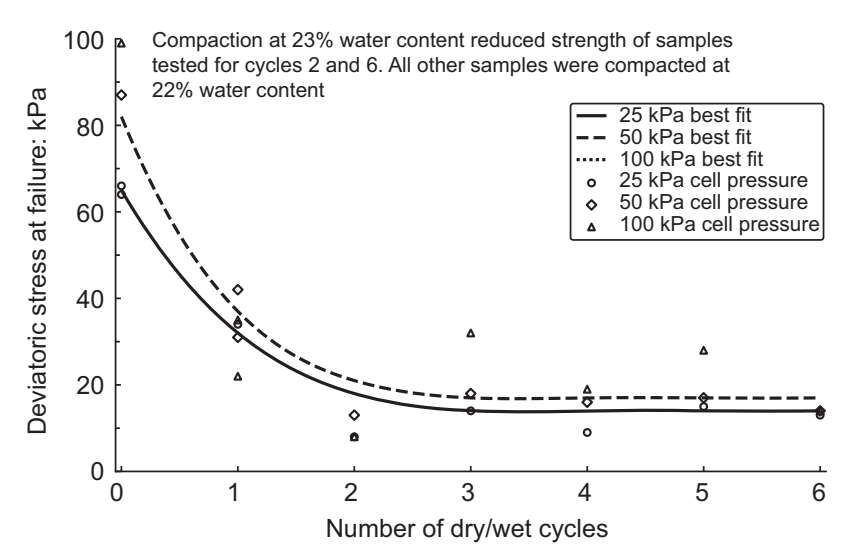

Fig. 2. The loss in strength observed after cycles of drying and wetting strength reduction over the first two cycles; however, for cycles 3 to 6 there is little further strength reduction.

Mendes \& Toll (2016) previously tested Nafferton soil, investigating the effects of drying back, or wetting up from an initial compacted state. They found that samples that are dried back to a particular water content had a higher strength than a sample compacted at that water content; conversely, a sample wetted to achieve that water content had a lower strength. The data presented here show that a full cycle of drying and wetting results in an overall loss of strength, which is exacerbated by further wet-dry cycles. This behaviour occurs up to a limiting number for cycles of a similar magnitude, the effect of exposure to larger cycles is discussed in the later section entitled 'Development of SWRC under environmental cycling'.

The effect of dry-wet cycles on tensile strength is a crucial factor in desiccation crack initiation and crack network development in clay-rich fills. The development of tensile strength with dry-wet cycling has been investigated using a direct tensile strength test described by Stirling et al. (2015). Crack initiation is assumed to occur by induced tensile stress brought about by restrained shrinkage due to surface desiccation exceeding the soil tensile strength. The development of tensile strength in clay soils with changing water content is related to (but not solely a result of) an inherent increase in matric suction. A cracking analysis on this basis indicates that crack initiation will occur at a given tensile strength, which exists at a specific water content. However, it has been found that reduced tensile strength is achieved upon cyclic wetting and drying, meaning the use of a single, initial drying relationship will result in an underestimation of subsequent crack network development. The relationship between tensile strength and water content established along an initial drying path has been considered as a main influence on the temporal and spatial distribution of cracking during progressive soil drying.

A programme of testing was conducted to investigate the tensile strength change with dry-wet cycles in Nafferton soil. This behaviour is presented in Fig. 3 for samples undergoing initial drying, wetting and subsequent re-drying. The initial drying path shows a trend of exponentially increasing tensile strength with decreasing water content. This path is fitted with the highest $R^{2}$ value; the confidence of fit is noted to reduce with each subsequent path. Upon wetting, a similarly exponential trend may be fitted. However, the wetting relationship follows much lower strength values and at water contents $>20 \%$, negligible tensile stress is maintained. The second drying path exhibits higher tensile strengths than that of the wetting trend, yet is considerably weaker than the initial drying curve.

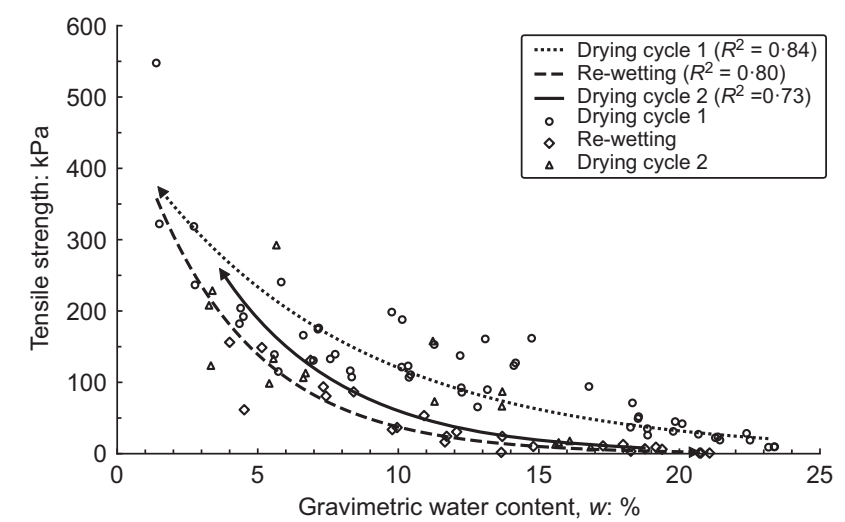

Fig. 3. Tensile strength trend upon initial drying, wetting and re-drying paths 
The reduction in tensile strength produced by cycling water content is evident, in addition to the hysteretic relationship between matric suction and water content, which is familiar in the study of soil wetting. In other words, in the context of soil-water retention, upon wetting, lower suction is developed at a given water content than would be generated upon drying. This effect may well contribute to the reduced strength shown along the wetting path, but cannot be the sole cause because of the continued reduction in tensile strength with cycles of water content.

In order to explain the reduction in strength with wet-dry cycles, a model of soil fabric deterioration is proposed, in which micro-cracks are developed during the initial desiccation stage that reduce the tensile strength that leads to crack initiation. This leads to irrecoverable deterioration of the structure of the compacted clay. This in turn causes stress concentrations in the intact clay fabric under further wet-dry cycles, which may reach the tensile limiting stress and cause crack propagation ultimately manifesting as an interconnected network of cracks with progressive cycles. This phenomenon, as documented by Tang et al. (2011) and Wang et al. (2017), has been further investigated herein using scanning electron microscopy (SEM), the results of which are described in the following section.

In summary, significant losses in shear and tensile strength are observed after each drying-wetting cycle, consistent with the reduced ability of the soil to generate a consistent level of suction. The underlying mechanism by which suction generation is reduced is proposed as the development of a matrix of cracking throughout the soil.

\section{MICROSTRUCTURAL CHANGE}

To investigate the presence of microstructural changes upon repeated drying, imaging at the nano/micrometre scale was carried out using an environmental scanning electron microscope (E-SEM). Specimens were prepared at water contents equivalent to the liquid limit and allowed to come to water content equalisation (sealed for $24 \mathrm{~h}$ ) before being statically compacted into $10 \mathrm{~mm}$ dia. circular steel specimen holders to a depth of $5 \mathrm{~mm}$. A drying environment was promoted by a reduction in pressure within the imaging chamber.

The samples were analysed using an FEI Company Quanta 600 ESEM equipped with an Oxford Instruments Inca Energy 450 energy-dispersive X-ray microanalysis (EDXA) system using a $50 \mathrm{~mm}^{2}$ Peltier-cooled silicon drift $\mathrm{X}$-ray detector (SDD). The samples were analysed without application of an electrically conductive coating. To control the sample moisture content and mitigate surface charging they were analysed under variable pressure conditions using a water vapour atmosphere and a Peltier-cooled stage. Drying was instigated by modifying chamber pressure, with the sample being held at $2^{\circ} \mathrm{C}\left( \pm 0.01^{\circ} \mathrm{C}\right)$ and adjusting the pressure to below the water liquidus (5.3 Torr). Wetting was conducted by removing the specimen from the chamber, and applying four droplets of deionised water before being resealed for re-equalisation. Electron beam conditions were: accelerating voltage $10-20 \mathrm{kV}$, spot sizes 5 (nominal beam current range of $0.95-1 \cdot 2 \mathrm{nA}$ ), working distance of 9.5-12 mm. SEM photomicrographs were obtained using backscattered electrons. Fig. 4 shows a single specimen subjected to a succession of three drying cycles and the crack pattern resulting from each drying stage. The images presented represent the end of drying - a chamber relative humidity of $100 \%$. Figs 4(a)-4(c) illustrate the development of an increasingly interconnected and propagating network of cracks. Figs 4(d)-4(f) show the disaggregation of the clay structure with each successive cycle.

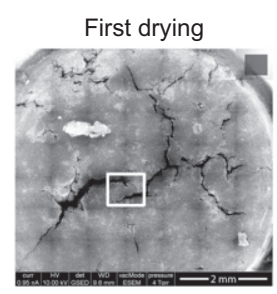

(a)

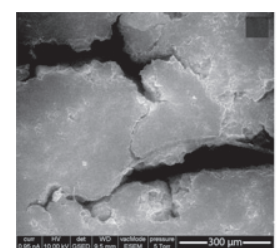

(d)

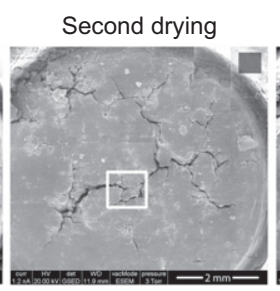

(b)

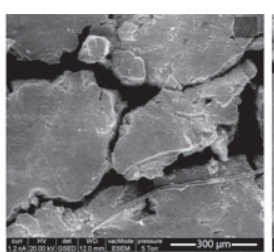

(e)

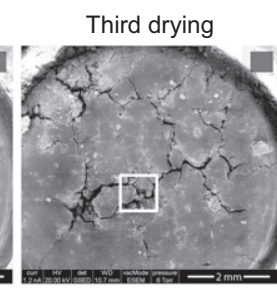

(c)

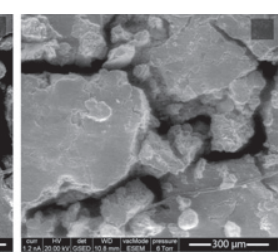

(f)
Fig. 4. Cracking and deterioration due to dry/wet cycling at the micro-scale: E-SEM. (d)-(f) ( $\times 100$ magnification) depict areas shown by white squares in (a)-(c) (×15 magnification)

The results illustrate that successive wetting and drying causes the development of a progressively increasing network of interconnected micro-scale cracks throughout the soil specimen. Similar results were observed in additional samples and by Azizi et al. (2019) when cycling a compacted silty clay through six wetting and drying cycles. This supports the hypothesis proposed to explain the progressive loss of strength due to wetting and drying as previously discussed. The emerging redistribution of pore sizes influences the ability of the soil to generate and sustain a consistent magnitude of matric suction under the same level of drying. Furthermore, the increase in macro-pore space due to microcracking and its impact on suction generation will alter the soil-water retention behaviour of specimens subjected to cyclic wetting and drying. This phenomenon was investigated through the production of soil-water retention curves (SWRCs) for specimens subjected to cycles of wetting and drying.

\section{DEVELOPMENT OF SWRC UNDER ENVIRONMENTAL CYCLING}

\section{Laboratory determination of cyclic SWRCs}

Soil-water retention curves define the relationship between water content and suction and represent a key aspect of understanding the unsaturated behaviour of soils. The SWRC testing apparatus developed by Toll et al. (2015) and Liu et al. (2020) was used because it allows continuous measurements of water content, suction and volume change. The measurement set-up consists of an electronic balance to determine the change in weight, and in turn gravimetric water content; displacement transducers for volume change measurements and a high-capacity tensiometer to measure suction. However, other techniques were also used, including pressure plate, filter paper and dew point potentiometer.

Laboratory testing of soil-water retention behaviour was performed on specimens of the Nafferton soil. Specimens were prepared by air drying and sieving to $<2.8 \mathrm{~mm}$ in order to improve homogeneity and consistency between specimens (Mendes, 2011), and compacted at 22\% water content into a $100 \mathrm{~mm}$ dia. mould using the equivalent effort of the standard $2.5 \mathrm{~kg}$ Proctor test. Specimens were trimmed to a diameter of $75 \mathrm{~mm}$ and a thickness of $20 \mathrm{~mm}$ for testing.

Figure 5 shows a suite of SWRCs expressed in both gravimetric and volumetric water content, as well as degree of 

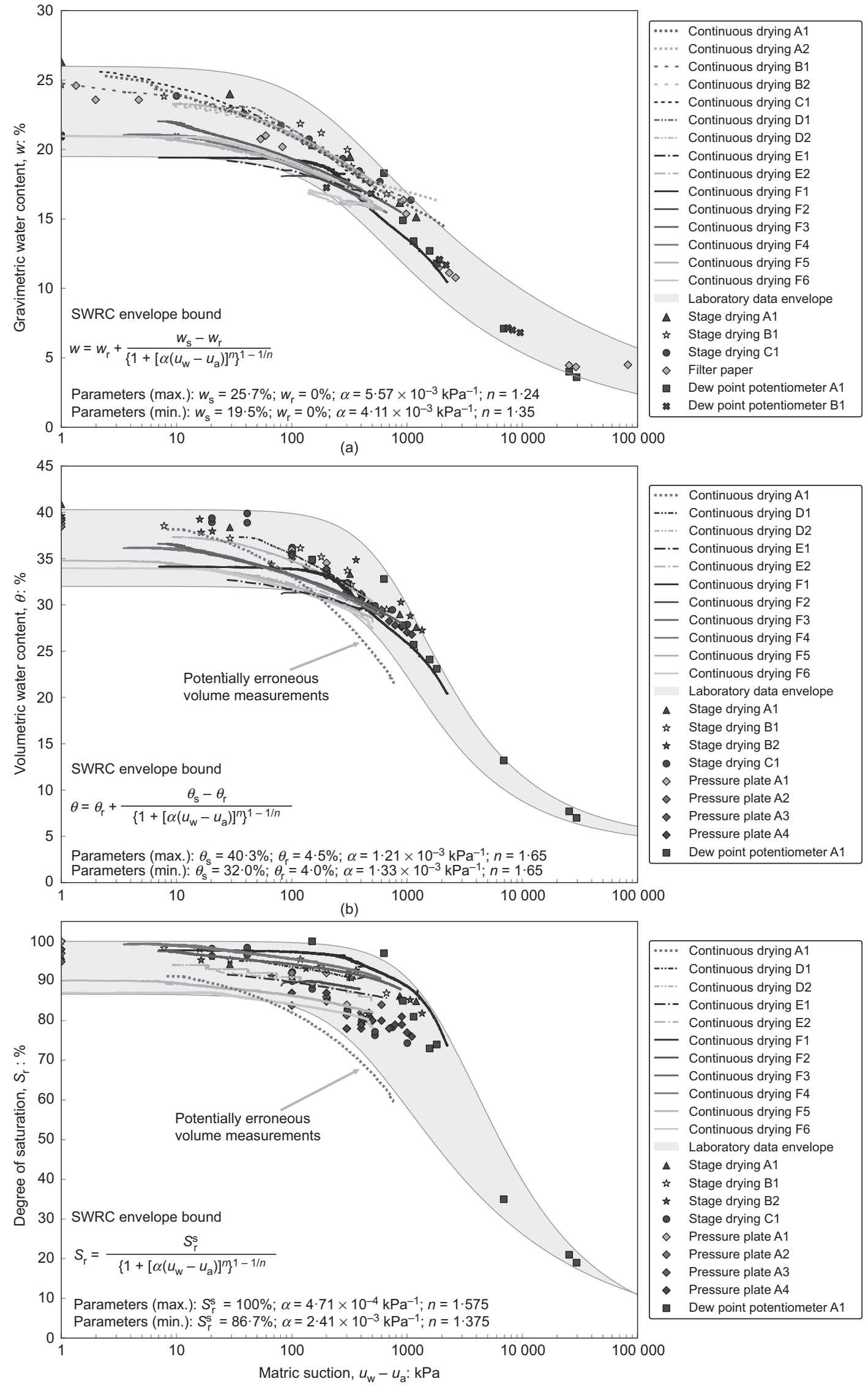

(c)

Fig. 5. Drying SWRCs in terms of: (a) gravimetric water content; (b) volumetric water content; (c) degree of saturation

saturation terms. Good agreement can be seen between the differing test methodologies, defining an initial drying path SWRC envelope (see figure). Specimens compacted wet of optimum (near saturation) influence the upper bound of this envelope, whereas specimens compacted nearer the optimum water content (20\% gravimetric water content) 
show a flatter response, narrowing the envelope as suction increases.

To investigate the influence of wet-dry cycles, drying paths were imposed by allowing specimens to dry slowly in a controlled environment, in which the temperature was maintained between $22.3^{\circ} \mathrm{C}$ and $23.3^{\circ} \mathrm{C}$ and the recorded relative humidity fluctuated from $46 \cdot 5 \%$ to $51 \cdot 1 \%$ during the tests. Wetting paths were imposed either manually or by applying a constant rate of water droplets through an automated wetting system. Specimens were positioned on a low-friction surface during the test; combined with the slow rate of drying, this reduced the potential for the formation of large $(>0.5 \mathrm{~mm})$ cracks during water content cycling, although micro-scale cracks as observed in Fig. 4 could still develop.

Figure 6 shows a test where the soil was initially prepared at $23 \cdot 3 \%$ gravimetric water content. It was allowed to dry until reaching a matric suction of $500 \mathrm{kPa}$. It was then wetted

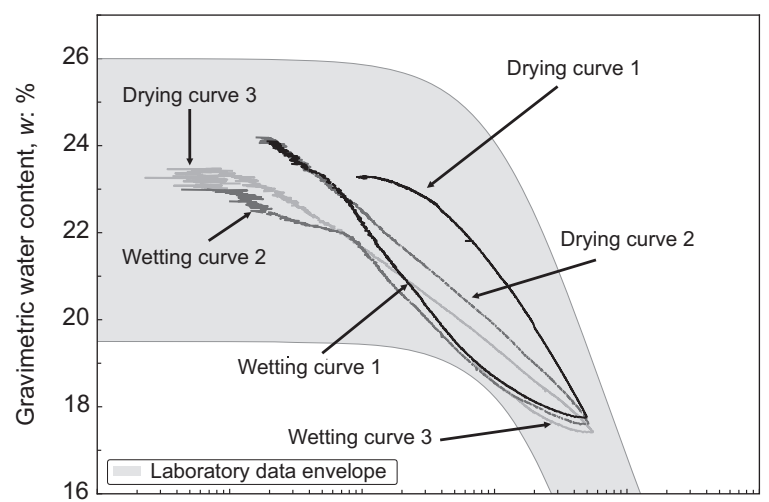

(a)

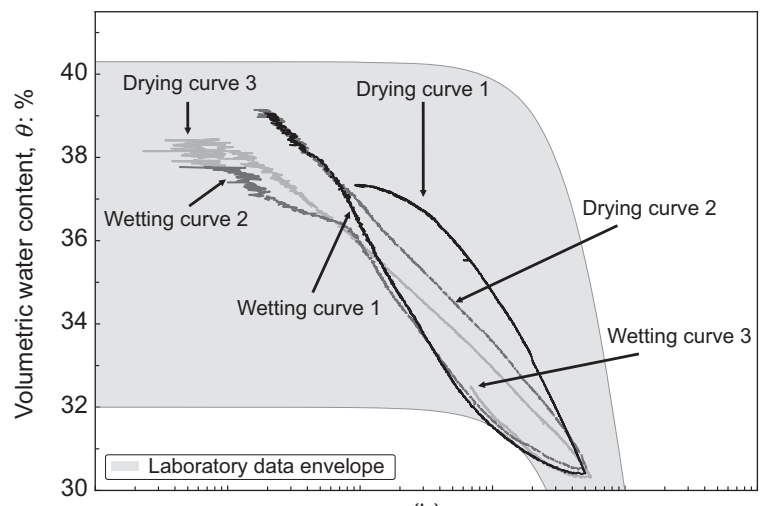

(b)

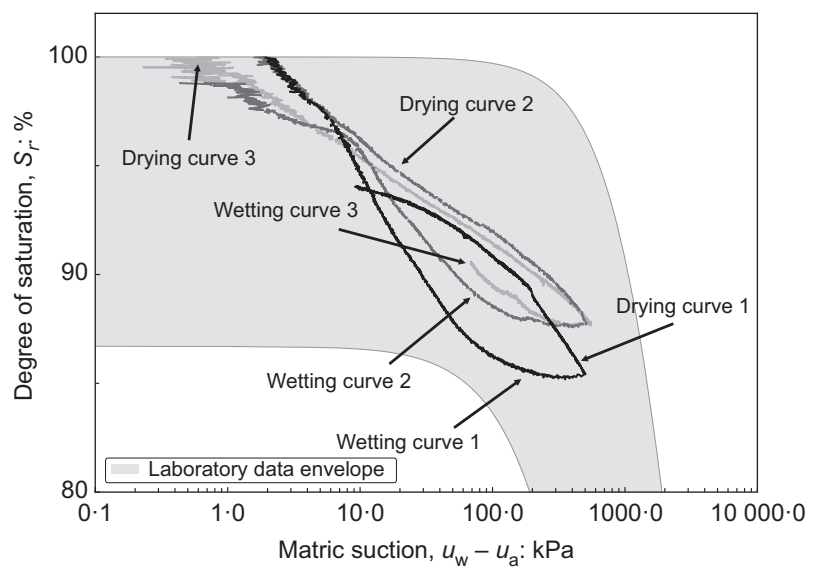

(c)

Fig. 6. Soil-water retention behaviour showing three cycles of drying/wetting in terms of: (a) gravimetric water content; (b) volumetric water content; (c) degree of saturation. Note that part (a) is modified from Stirling et al. (2017) to $24 \cdot 1 \%$, before drying again to achieve a suction of $500 \mathrm{kPa}$. It was wetted again to a water content of $23 \cdot 6 \%$ before a final drying stage back to $500 \mathrm{kPa}$. The test shows a progressive shift to lower suction at the same water content with each cycle of drying and wetting. If comparisons are made at a gravimetric water content of $22 \cdot 0 \%$, the first drying cycle shows a suction of $58 \mathrm{kPa}$, the second drying cycle shows $14 \mathrm{kPa}$ and the third drying cycle shows $7 \mathrm{kPa}$. This demonstrates a significant loss of suction (at the same water content) with each wet-dry cycle.

Additional SWRC test results under further wet-dry cycles were conducted between two fixed water contents, namely $20 \%$ and $15 \%$ (Liu et al., 2020), and showed the same trend of a loss of suction with each cycle. The largest shifts are observed to occur in the first four cycles, with a smaller reduction in suction produced between the fourth and sixth cycles. These results corroborate the proposed mechanism behind the reduction in shear strength demonstrated in Fig. 1 whereby a change in fabric (as demonstrated in Fig. 4) brought about by successive wet-dry cycles reduces the ability to generate and retain suction.

Dry-wet cycles cause a shift in the SWRCs, as demonstrated in Fig. 6, but if cycling continues over the same suction range, then the movement in the curves stops after 3-4 cycles (Alonso et al., 2005; Liu et al., 2020). The soilwater retention behaviour then becomes quite repeatable. However, Fig. 7 shows that if a sample is subject to wet-dry cycles where the suction is increased beyond that which has been experienced before, the wetting/drying loop (scanning curve) shifts downwards because of progressing further down the main drying curve before being subject to wetting. This means that each time drying progresses beyond the prior maximum suction value that an asset has been subject to, due to a more extreme drying event than has occurred in its past history, an additional deterioration in performance due to the effect of suction loss can be expected (i.e. for a given water content, lower suction magnitudes are generated). As such, the same mechanism can cause progressively greater deterioration over the life of an asset, each time it is subject to an extreme event. UKCP18 projections (Lowe et al., 2018) suggest that a future climate is likely to include hotter, dryer summers, and as such it is possible that this mechanism may become more important in the future.

\section{Long-term field determination of SWRCs}

Testing of homogenised specimens in the laboratory has demonstrated clearly the potential shift in SWRC due to wet-dry cycling. To establish the influence of this

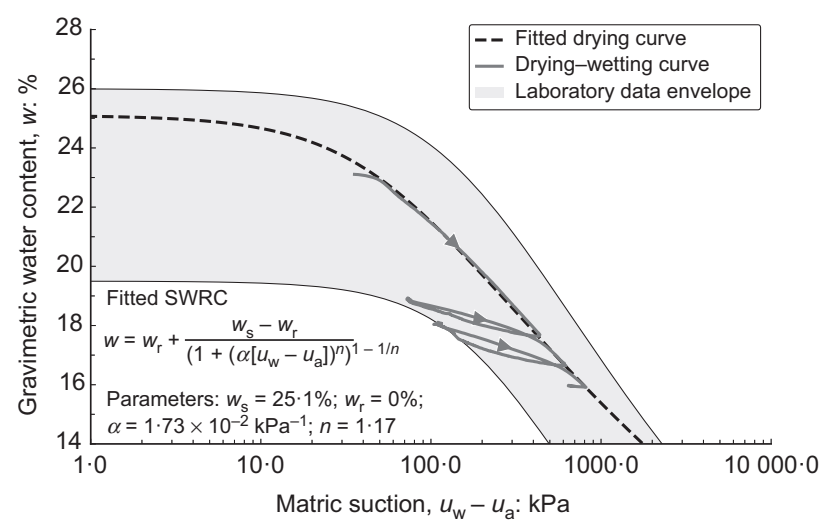

Fig. 7. Drying/wetting cycles where suction is increased with each drying cycle. Fitted curve was derived from the van Genuchten (1980) equation in terms of gravimetric water content 


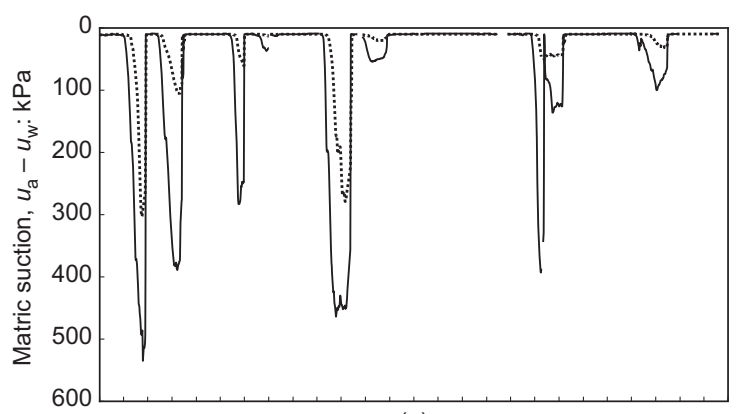

(a)

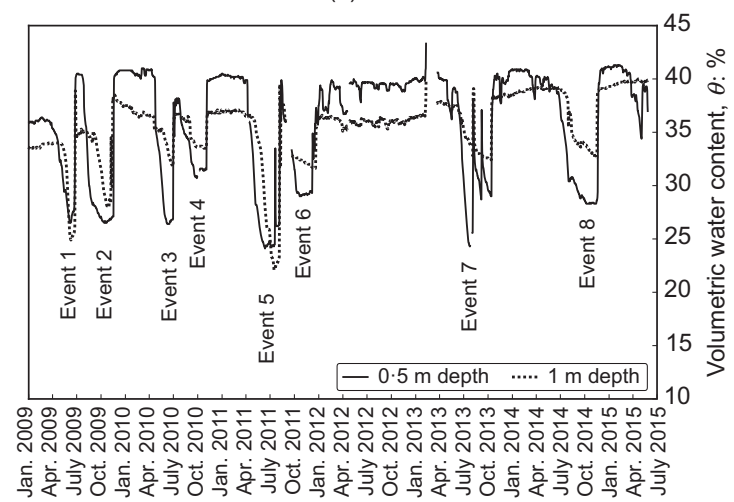

(b)

Fig. 8. (a) Suction and (b) volumetric water content at the lower slope position at 0.5 and $1.0 \mathrm{~m}$ depth within the Bionics test embankment (Stirling et al., 2017)

behaviour in situ, long-term data sets from the Bionics test embankment, comprising the as-placed engineered fill, have been used to generate in situ SWRCs.

The data presented in Fig. 8 were obtained using sensors (Decagon Devices: EC-TM, MPS-1 and MPS-2 models). These were installed at an upper ( $3 \mathrm{~m}$ down slope from the crest) and lower ( $3 \mathrm{~m}$ up slope from the base) position on the south-facing aspect of the test embankment slope. The EC-TM measures the dielectric permittivity of the soil to determine the volumetric water content, while the MPS- $1 / 2$ measures permittivity across a ceramic disc in equilibrium with the soil water to determine the water potential (suction). Technical specifications for these sensors may be accessed directly from the manufacturer's literature (Meter Group, 2019).

The time series shown in Fig. 8 are from the lower monitored position at 0.5 and $1.0 \mathrm{~m}$ vertically below the ground surface, with a spacing of no more than $150 \mathrm{~mm}$ between the water content and suction sensors. Given the measurement range of the sensor $(-10$ to $-600 \mathrm{kPa})$, only negative pore pressures have been recorded leaving positive pore pressure data uncaptured during 'wet' conditions (seen as near zero in Fig. 8(a)). The pore pressure response to precipitation and estimated recharge is further discussed in Glendinning et al. (2014).

The results show, over the period 2009 to 2015, eight major drying events. Maximum generated suctions of $300 \mathrm{kPa}$ and $535 \mathrm{kPa}$ were recorded at 1.0 and $0.5 \mathrm{~m}$ depths, respectively, comfortably within the instrument sensitivity range. In comparison, the extended period of high precipitation experienced in the UK during the summer of 2012 is shown to have inhibited the generation of summer suctions at both monitored depths.

Multiple drying events have been recorded within a given (predominantly) summer period. This highlights that wet-dry cycles cannot be assumed to have annual periodicity and are instead potentially more frequent. Overall, a range of maximum drying event suction magnitudes are achieved throughout the monitored period while volumetric water content is observed to consistently fluctuate within the range $25-40 \%$

The start and duration of these events varies between instrumented position and depth. Typically, the upper monitored position toward the shoulder showed an earlier onset of drying than the lower position, which is likely to be due to greater wind exposure, although a similar wetting up time was experienced at both positions. In terms of depth, drying at $0.5 \mathrm{~m}$ was observed to begin 10-25 days earlier than at $1.0 \mathrm{~m}$ depth. This is due to the shallower region being closer to the atmospheric boundary and the greater effect of root-water uptake in the more densely rooted zone.

The start of each drying event is consistently defined as the time at which an increase in suction from the instrument baseline of $10 \mathrm{kPa}$ occurs. This is because the laboratoryderived SWRCs indicate that suctions of the order of $100 \mathrm{kPa}$ may exist prior to any noticeable change in water content for this material. Therefore, the onset of drying is based on suction (rather than water content) in order to capture the true start of each event. The end of each event is characterised by a loss of suction due to the onset of precipitation and also associated with a rapid increase in water content. The corresponding volumetric water content and suction data from these eight events have been compiled to produce in situ SWRCs at an upper and lower slope position (Stirling et al., 2017). The resulting SWRCs are presented in Fig. 9. The envelope of drying data derived from the laboratory testing is illustrated in grey for comparison. It was not possible to include event 4 in the plot of values from the lower slope at $1.0 \mathrm{~m}$ depth due to insufficient drying to generate a measurable suction. Values for event 7 from the upper slope at both $0.5 \mathrm{~m}$ and $1.0 \mathrm{~m}$ depth are not present due to hardware malfunction.

The SWRCs from wetting events are not presented in Fig. 9 because the temporal resolution of the long-running data logger is insufficient to capture data points to credibly derive a wetting curve due to the high rate at which suction is dissipated following precipitation (see Fig. 8). In the time between each drying event, the ground is noted to have reached full saturation at the monitored depths. During construction of the test embankment, samples taken after each successive lift enabled porosity conditions at the time of construction to be determined. These ranged between 0.395 and $0 \cdot 354$, decreasing with depth (Glendinning et al., 2014). The return to full saturation indicates that the varying field drying curves represent changes to the primary curves due to wet-dry cycles. As such they are potentially a function of the deterioration mechanisms outlined previously, rather than representing scanning lines between fixed wetting and drying curves, which is how they may have been interpreted prior to the evidence for deterioration in the water-retention capacity due to wet-dry cycles.

The drying curves derived from the field data show a pronounced shift in the first three cycles of significant wetting and drying summarised as events 1,2 and 3, which in all cases exceed $300 \mathrm{kPa}$ suction at $0.5 \mathrm{~m}$ depth and $50 \mathrm{kPa}$ suction at $1 \mathrm{~m}$, with reduced variation in subsequent cycles. The initial, as-constructed drying curve (see event 1 curves in Fig. 9) consistently exhibits sustained saturation over a greater suction range and a higher interpreted air entry value (AEV) where desaturation is initiated. Subsequent drying events (sequentially lighter shading) display lower AEVs - that is a reduced capacity to maintain a suction at both full saturation and for a given magnitude of drying, as seen in laboratory controlled testing. It is believed that this change in behaviour is in some part related to the increased 


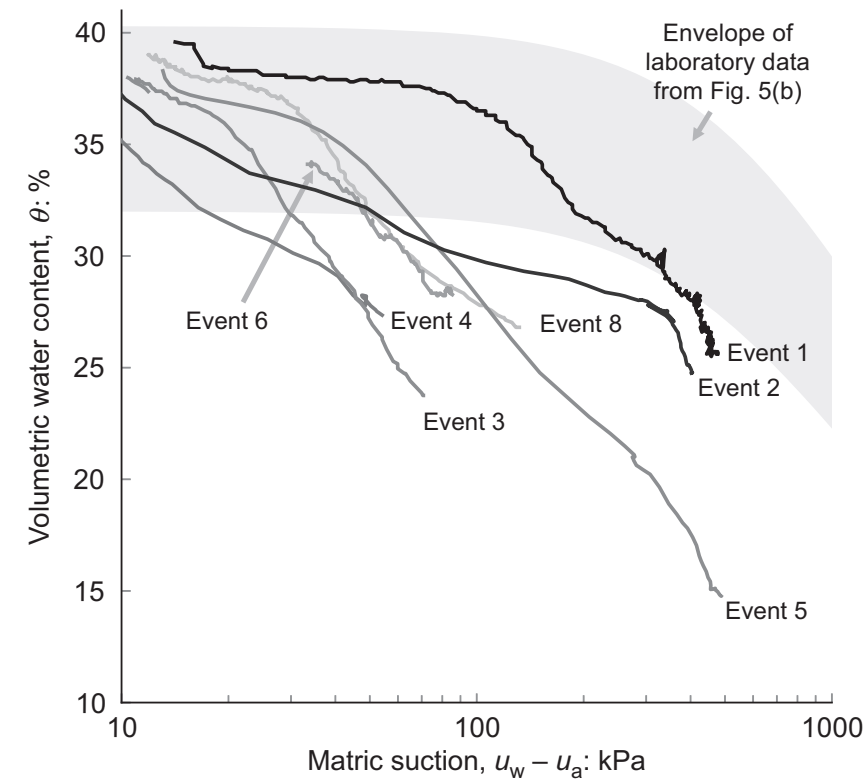

(a)

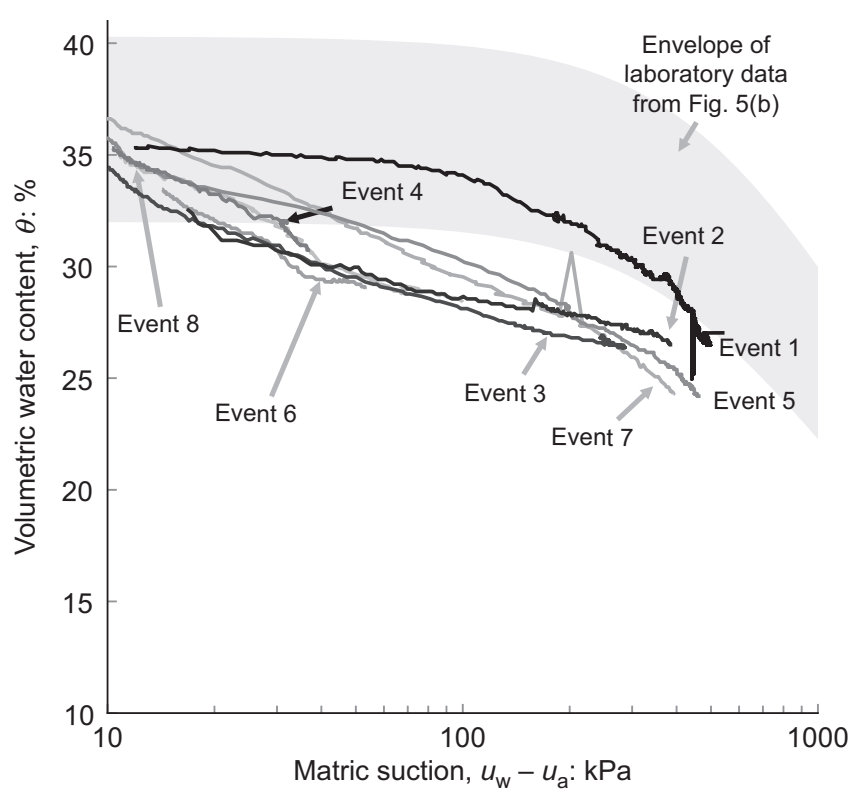

(c)

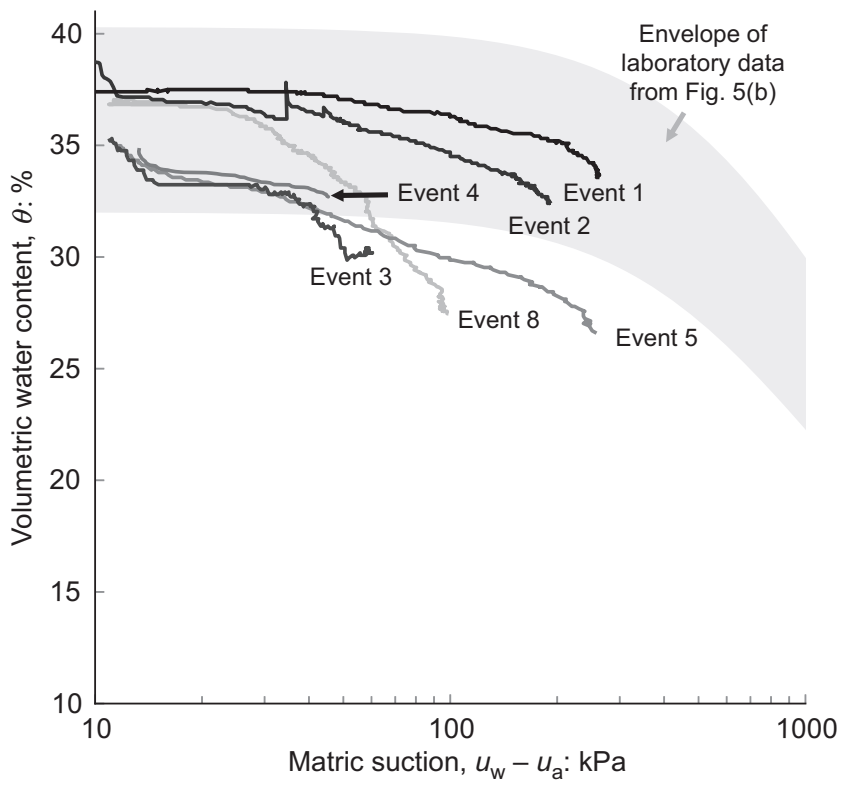

(b)

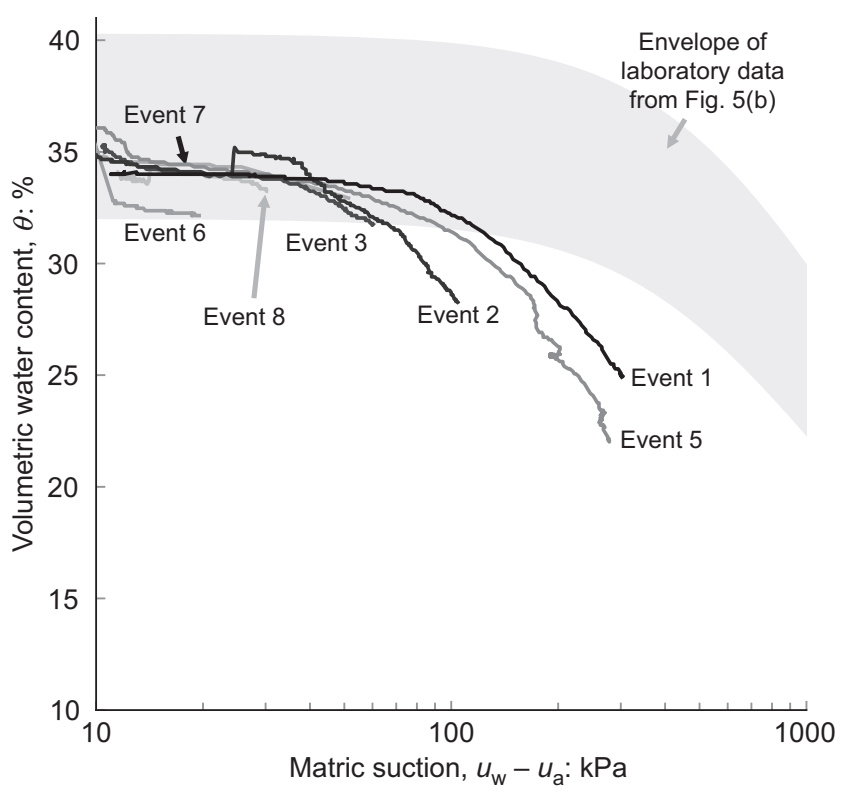

(d)

Fig. 9. SWRCs as measured in situ at lower and upper slope positions at 0.5 and $1.0 \mathrm{~m}$ depth between 2009 and 2015: (a) upper slope, $0.5 \mathrm{~m}$ depth; (b) upper slope, $1.0 \mathrm{~m}$ depth; (c) lower slope, $0.5 \mathrm{~m}$ depth; (d) lower slope, $1.0 \mathrm{~m}$ depth; Event data from Stirling et al. (2017)

proportion of larger pore space, as these pores are less able to sustain suction. This shift in pore geometry distribution is a result of micro-scale soil fabric changes probably attributable to extremes in shrink-swell experienced by the soil between drying events. The formation of enlarged void spaces and increased pore connectivity can also be seen to have resulted in non-uniform drying paths where the sudden changes in the gradient of the drying curves are thought to represent dual or multiple air entry stages resulting from the development of a heterogeneous pore system (see e.g. Durner (1994)).

It is important to note that the Bionics embankment was constructed in 2005, with the instrumentation used for in situ SWRC analysis installed in 2008. Although the greatest change is observed in the early monitored cycles, as discussed in the earlier section 'Laboratory determination of cyclic SWRCs', the variability of weather determines the extent to which permanent deterioration is caused, with ever more extreme drying (i.e. progression along the bounding drying curve) governing the reduction in suction generation capability.

\section{DETERIORATION AT THE MACRO-SCALE}

It is proposed that, when subjected to wet-dry cycles, the soil microstructural deterioration (highlighted previously) progresses to the extent that, with sufficient drying, macroscale surface cracking is initiated. These features are an indicator of the deterioration of an infrastructure slope. It is also proposed that these cracks are a means through which weather-driven slope deterioration penetrates deeper into the soil subsurface, developing a 'deterioration front'.

The mechanism driving the progression of the deterioration front is that, as cracks propagate, they provide an enhanced pathway for water infiltration and removal at greater depths. This in turn causes shrink-swell cycles at depth that would not otherwise have occurred, driving 
further crack development and propagation of the crack network. As the near-surface permeability increases due to increasing porosity, the ability to generate and maintain suctions decreases. The resultant reduction in tensile stresses acts to limit crack formation. This in combination with the higher confining stresses at greater depth leads to an increase in tensile strength, which in turn limits the depth to which further crack-driven deterioration can propagate.

To understand the behaviour of desiccation cracks at full scale on grass vegetated slopes, three linear transducers were installed across an active crack site on the south-facing 1 in 2 slope at the Bionics embankment. Volumetric water content and matric suction adjacent to the cracks, and rainfall together with the presence of run-off, were used as indicators of the impact of cracking on the depth of deterioration. The monitoring equipment and the approximate location of the cracks on the embankment can be seen in Fig. 10.

Monitored crack aperture data recorded between May 2015 and November 2016 are presented in terms of transducer displacement in Fig. 11. The corresponding volumetric water content and matric suctions are presented from a monitoring profile $1.6 \mathrm{~m}$ away from the crack site. Rainfall and reference evapotranspiration (ETo) data are also presented for the same period, as well as directly measured run-off.

The measurements indicate the onset of crack opening at the start of June. This is concurrent with the onset of suction generation as measured at $0.5 \mathrm{~m}$ depth and follows a period of limited rainfall and high ETo. Once open, a series of rainfall events partially dissipate suction and cause a rapid reduction in crack aperture (highlighted). Continued high levels of ETo during this period maintain suctions between

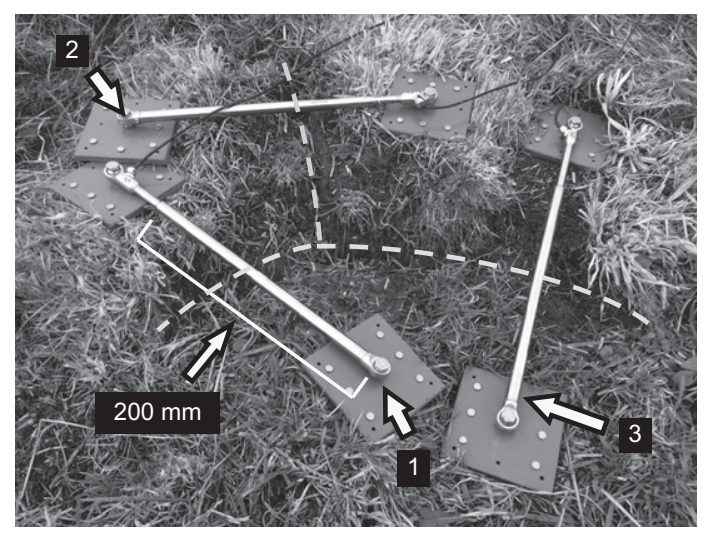

(a)

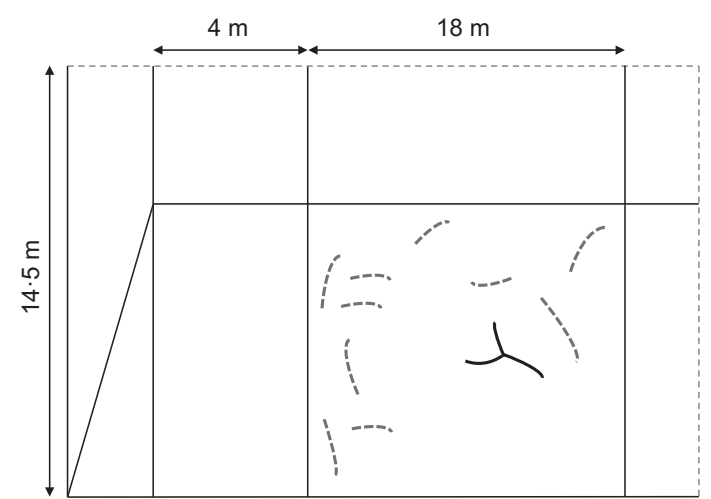

(b)

Fig. 10. (a) Linear transducer crack-monitoring system (crack shown by dashed line). (b) Schematic diagram of crack distribution on the monitored embankment slope (monitored crack shown by solid line)
200 and $320 \mathrm{kPa}$, enabling the crack to re-open between the three major rainfall events. Following the fourth highlighted rainfall event, total ETo reduces and rainfall dominates. Crack aperture reduces consistently from October to midNovember 2015, with closure (return to original displacement in transducers 1 and 2) concurrent with suction dissipation.

During the 2015-2016 winter, little displacement is evident on the monitored crack. High water content suggesting saturated conditions results in run-off following high rainfall (see January 2016). In 2016, the crack aperture is shown to open in May during a period of sustained high ETo and low rainfall. The rapid response of crack displacement to rainfall events is repeated, although unlike the previous year, a wet period during late June to July limited the development of deeper suctions and resulted in measurable run-off.

There exists a clear connectivity between cracking, near-surface $(<1 \mathrm{~m})$ saturation and run-off. Taking the period May 2015-May 2016, despite relatively high rainfall during the active crack season, no run-off is measured. Conversely, once the crack is closed (mid-November 2015 onwards), run-off is produced from similar magnitude rainfall events. The occurrence of run-off is a function of surface saturation and the presence of open cracks on the slope surface. These cracks enhance surface hydraulic conductivity and intercept run-off; this in turn increases the potential for greater magnitude of pore pressure fluctuation.

In situ, near-surface $(<1.5 \mathrm{~m})$ saturated hydraulic conductivity measurements were carried out at the Bionics embankment to investigate variability due to environmental cycling (Dixon et al., 2019). This study is based on 85 individual measurements made in summer months (June to August) over the period 2009-2014. Large variability in hydraulic conductivity in the uppermost $1.0 \mathrm{~m}$ was observed, with values in the top $0.8 \mathrm{~m}$ having a range from $1 \times 10^{-4}$ to $5 \times 10^{-10} \mathrm{~m} / \mathrm{s}$ (i.e. over five orders of magnitude) and a marked reduction in hydraulic conductivity with depth. Therefore, the near-surface zone is evidently affected by exposure to weather-driven deterioration and the resultant development of macro-scale, crack features.

\section{DISCUSSION: A PROPOSED WEATHER-DRIVEN SOIL DETERIORATION MODEL FOR EMBANKMENT SLOPES}

The work presented in this paper provides the evidence for the existence of a process of weather-driven deterioration of compacted clay fills and is summarised in Fig. 12. Post compaction, the action of successive wetting and drying, caused by both seasonal and higher frequency weather cycles, result in the soil at the near surface undergoing irrecoverable changes in microstructure caused by repeated shrinkage and swelling. This manifests as a matrix of micro-cracks that increase in aperture and interconnectivity, leading to a greater porosity of the soil micro-fabric with increasing numbers of wet-dry cycles.

The increasingly porous soil loses the ability to generate the same magnitude of suction at a given water content, as observed in the SWRCs at both laboratory and field scale. This causes the inferred AEV (where rapid desaturation is initiated) to decrease with increasing numbers of wet-dry cycles. This in turn influences the movement of water into and out of the slope by controlling the rate of evapotranspiration and infiltration. The progressive rates of change observed in soil-water retention, driven by wetting and drying, are non-linear, with the greatest change being observed after the initial, primary drying. However, further changes continue, albeit at a slower rate, as a result of continuous cycling. An extreme event (i.e. a longer, more intense drying 

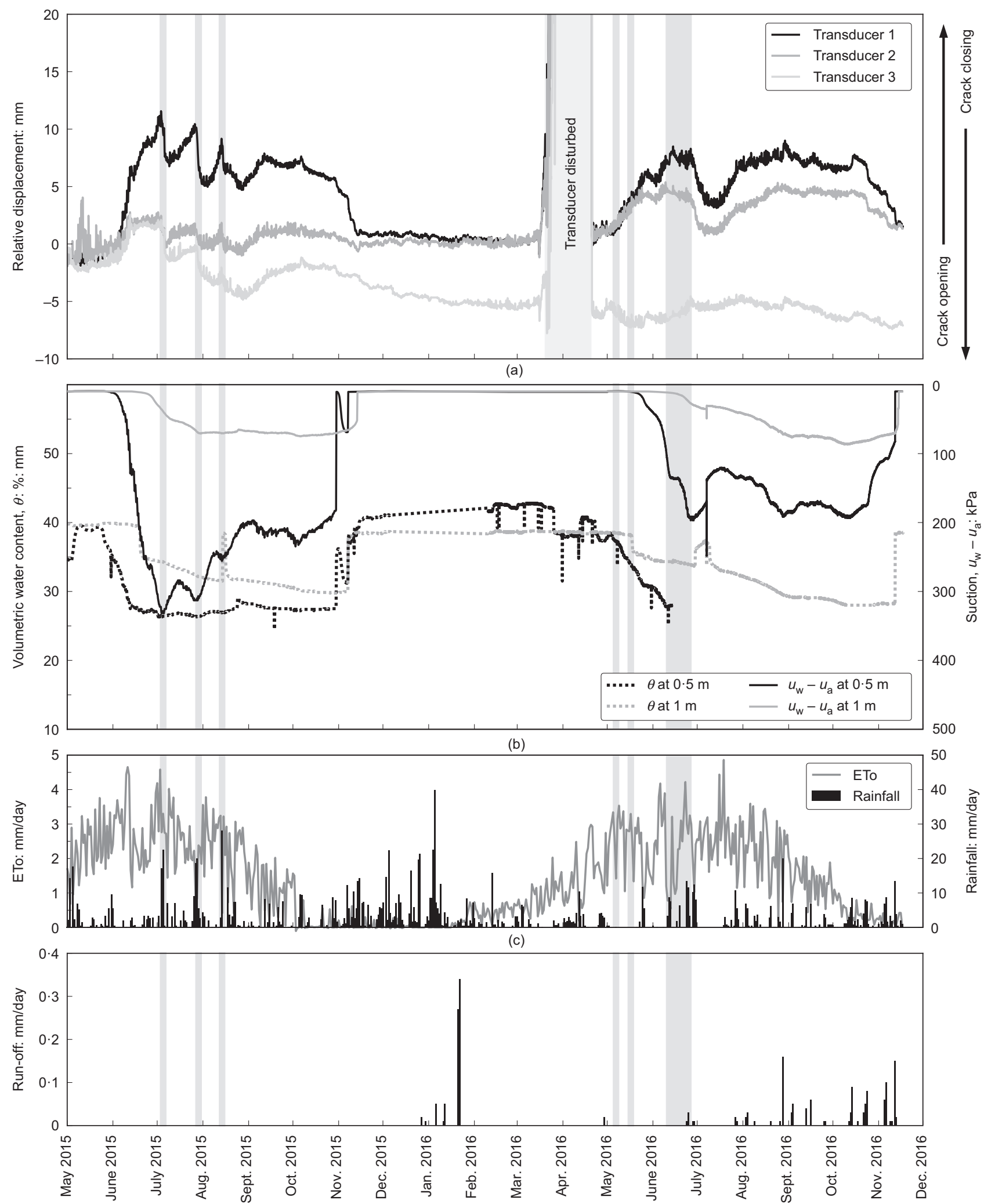

(d)

Fig. 11. (a) Crack displacement correlated with (b) water content and suction; (c) ETo and rainfall and (d) run-off (after Stirling et al. (2017))

event than any previously experienced) causes a renewed increase in the rate of deterioration. Therefore, if climate change causes an increase in both magnitude and severity of these events (as included in future UKCP18 scenarios, see Lowe et al. (2018)), then it is possible that increased deterioration of soil-water retention properties will occur in the future.
Changes in the capacity to generate soil suction also result in loss of shear strength, which is most pronounced following the initial cycles, consistent with the loss of suction observed in SWRCs, and the reduction in shear strength seen in triaxial testing. This loss of strength can result in the shallow surface failures observed in engineered slopes post construction (Briggs et al., 2017). Any change in the ability of a soil to 


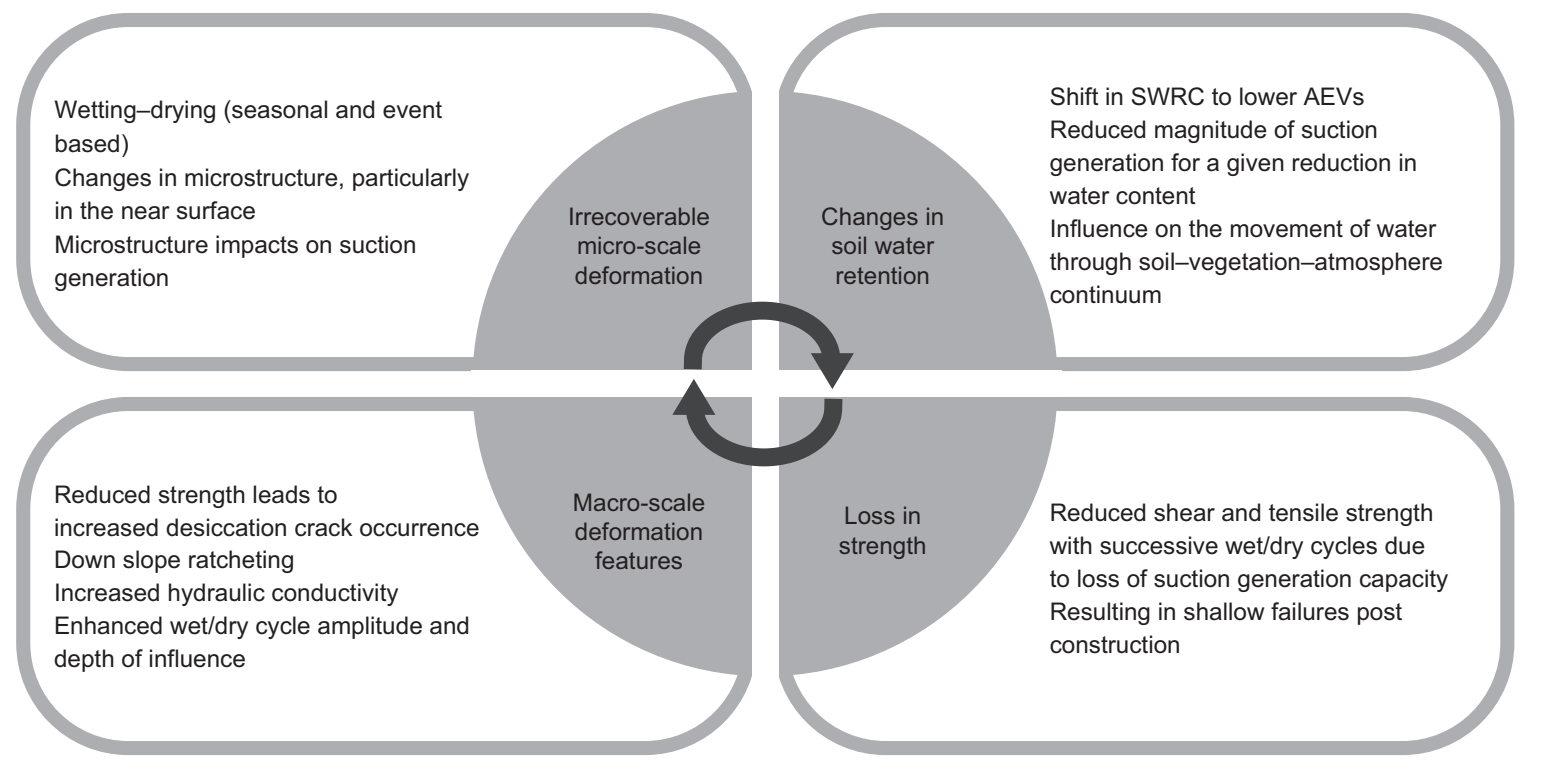

Fig. 12. Conceptual model of weather-driven clay fill deterioration

maintain suctions will also have implications for the stability of cut slopes, which rely partly on construction-induced negative pore pressures, the dissipation of which can influence stability (Vaughan \& Walbancke, 1973). Continued cycles can cause additional reduction in strength following extreme drying events that force suctions past the previous maximum. As described for the soil-water retention behaviour, this mechanism may become more significant in future.

Loss of suction also results in a progressive reduction in tensile strength, which leads to the propagation of desiccation cracks. The micro-scale effects described previously also have implications at the macro scale, where, for example, the increasing crack network will expose previously unaffected soil to the effects of wetting and drying, thus perpetuating the deterioration process and increasing the depth to which deterioration penetrates. There is evidence that cracks in slopes can penetrate to a depth of approximately $1 \mathrm{~m}$ (Anderson et al., 1982; Dyer et al., 2009) and that a hydrologically distinct layer exists in the top $1.5 \mathrm{~m}$ of a clay slope (Ng et al., 2003). An increase in permeability has been observed to vary by up to five orders of magnitude at the near-surface $(<0.6 \mathrm{~m})$ permeability (Dixon et al., 2019).

The progressive failure described by Leroueil (2001) requires changes in the soil properties, which are attributed in part to weathering. The weathering process in clay is in part a combination of cracking (and the resultant enhanced surface hydraulic conductivity) and loss of strength due to a reduced ability to generate and maintain suction. This reduction in shear strength can cause down-slope movements which, if large enough, can result in strain softening and the redistribution of load. Ultimately, changes in loading or further weather-driven deterioration could lead to slope failure.

It is postulated that cracking due to the action of wetting and drying and the resultant loss of strength and water retention capacity, along with increased permeability, is a pre-cursor to the initiation of progressive failure. This causes the soil at the near surface of an engineered clay slope to reduce in strength due to meteorological cycling without any change in external load.

The implications of this work are several fold. The first is that engineered clay slopes are likely to deteriorate as a result of wetting and drying action alone, which could result in failure as some critical reduction in strength is reached.
The second is that, when assessing the long-term stability of an engineered slope, the result should not be viewed as static: the soil properties are changing gradually due to seasonal cycling as a result of shrinking and swelling; superimposed on this is the response to discrete extreme events, which can cause sudden progression of deterioration, and which may act as failure triggers if a critical magnitude of deterioration is surpassed. Third, any assessment should consider a range of parameters and ground models reflecting the timedependent nature of the material properties. Modelling weather and climate impacts on slope stability requires the ability to model soil-atmosphere interaction, yet current hydro-mechanical coupled models are still unable to account for many deterioration mechanisms - for example, elevated, transient hydraulic conductivity due to cracking at the slope scale, shifting SWRCs both temporally and spatially, and the resultant effects on suctions and therefore to soil strength. New constitutive models for engineered soils are required that can capture these phenomena if the long-term stability of infrastructure slopes are to be assessed.

\section{CONCLUSIONS}

A new mechanism of soil deterioration driven by cyclic wetting and drying is proposed, based on an extensive laboratory and field experimental programme. The underlying cause for this deterioration is the microstructural changes to the soil fabric that lead to a loss in the ability to generate and maintain suction, causing a loss of strength. These changes in turn result in macrostructural features, such as cracking. Coupled together, these alterations in the fabric lead to changes in hydraulic conductivity, as well as significant reductions in shear strength which will have implications for seasonal ratcheting deformations, strength reduction and ultimately failure.

The rate of deterioration is non-linear, with the greatest observed change occurring after the initial, primary drying of newly compacted soil. However, further changes continue to develop with continuous cycling, additional changes occur suddenly, with the occurrence of discrete extreme weather events. The current evidence from UKCP09 and UKCP18 suggests that these events will increase in frequency due to climate change in the future. The above has implications for slope stability assessment, including the need for 
changeability of soil parameters and ground model due to the time-dependent nature of the deterioration processes proposed. There is a need for new constitutive soil model(s) that can account for soil deterioration due to wetting and drying in order to assess properly the impacts of weather and climate change on the long-term stability of engineered clay slopes. This work develops a conceptual framework and it is intended that the results presented will enable the formulation, calibration and validation of such constitutive models capable of capturing the deterioration mechanism.

The improved understanding of these mechanisms, as provided by this work, has the potential to more effectively forecast the conditions that cause deterioration and lead to failure, permitting asset owners to invest in more effective pro-active remediation, reducing the number of unanticipated failures, improving the resilience of the asset to climate change and substantially reducing the economic impact.

\section{ACKNOWLEDGEMENTS}

The work presented is an output of the collaborative research project iSMART (grant number EP/K027050/1) and the programme grant ACHILLES (programme grant number EP/R034575/1) funded by the UK Engineering and Physical Sciences Research Council (EPSRC). The authors would like to acknowledge Stephen Richardson, Jonathan Murphy and Stefan Frangov for laboratory testing and express their gratitude to Jeremy Rushton of the British Geological Survey Petrography and Microanalysis Laboratories for help and advice regarding the environmental scanning electron microscopy. The authors would also like to thank the students and researchers, T. Noguchi, A. Fraser, P. Osinski, G. Liu, R. Hen-Jones, F. Bertolini and A. Wilson, who contributed to some of the experiments.

\section{NOTATION \\ $p$ mean total stress \\ $p^{*}$ mean 'Bishop stress' \\ $q$ deviator stress at failure \\ $S_{\mathrm{r}}$ degree of saturation \\ $u_{\mathrm{a}}$ pore air pressure \\ $u_{\mathrm{w}}$ pore water pressure \\ $u_{0}$ initial pore water pressure \\ $w$ gravimetric water content \\ $\theta \quad$ volumetric water content}

\section{REFERENCES}

Alonso, E. E., Romero, E., Hoffmann, C. \& García-Escudero, E. (2005). Expansive bentonite-sand mixtures in cyclic controlledsuction drying and wetting. Engng Geol. 81, No. 3, 213-226, https://doi.org/10.1016/j.enggeo.2005.06.009.

Anderson, M. G., Hubbard, M. G. \& Kneale, P. E. (1982). The influence of shrinkage cracks on pore-water pressures within a clay embankment. Q. J. Engng Geol. Hydrogeol. 15, No. 1, 9-14, https://doi.org/10.1144/GSL.QJEG.1982.015.01.03.

Azizi, A., Musso, G. \& Jommi, C. (2019). Effects of repeated hydraulic loads on microstructure and hydraulic behaviour of a compacted clayey silt. Can. Geotech. J. 57, No. 1, 100-114, https://doi.org/10.1139/cgj-2018-0505.

BBC (2014). UK storms destroy railway line and leave thousands without power. $B B C N e w s, 5$ February. See https://www.bbc.co. uk/news/uk-26042990 (accessed 25/01/2019).

BBC (2017). Watford train crash: landslip risk 'was not identified'. $B B C$ News, 10 August. See https://www.bbc.co.uk/news/ukengland-beds-bucks-herts-40885490 (accessed 25/01/2019).

Bishop, A. W. (1959). The principle of effective stress. Tecknisk Ukeblad 106, No. 39, 859-863.

Briggs, K. M., Loveridge, F. A. \& Glendinning, S. (2017). Failures in transport infrastructure embankments. Engng Geol. 219, 107-117, https://doi.org/10.1016/j.enggeo.2016.07.016.
Dixon, N., Crosby, C. J., Stirling, R., Hughes, P. N., Smethurst, J., Briggs, K., Hughes, D., Gunn, D., Hobbs, P., Loveridge, F., Glendinning, S., Dijkstra, T. \& Hudson, A. (2019). In situ measurements of near-surface hydraulic conductivity in engineered clay slopes. Q. J. Engng Geol. Hydrogeol. 52, No. 1, 123-135, https://doi.org/10.1144/qjegh2017-059.

Durner, W. (1994). Hydraulic conductivity estimation for soils with heterogeneous pore structure. Water Resour. Res. 30, No. 2, 211-223, https://doi.org/10.1029/93WR02676.

Dyer, M., Utili, S. \& Zielinski, M. (2009). Field survey of desiccation fissuring of flood embankments. Proc. Instn Civ. Engrs - Wat. Manage. 162, No. 3, 221-232, https://doi.org/10.1680/wama. 2009.162.3.221.

Glendinning, S., Hall, J. \& Manning, L. (2009). Asset-management strategies for infrastructure embankments. Proc. Insth Civ. Engrs - Engng Sustain. 162, No. 2, 111-120, https://doi.org/ 10.1680/ensu.2009.162.2.111.

Glendinning, S., Hughes, P., Helm, P., Chambers, J., Mendes, J., Gunn, D., Wilkinson, P. \& Uhlemann, S. (2014). Construction, management and maintenance of embankments used for road and rail infrastructure: implications of weather induced pore water pressures. Acta Geotech. 9, No. 5, 799-816, https://doi.org/ 10.1007/s11440-014-0324-1.

Hudacsek, P., Bransby, M. F., Hallett, P. D. \& Bengough, A. G. (2009). Centrifuge modelling of climatic effects on clay embankments. Proc. Insth Civ. Engrs - Engng Sustain. 162, No. 2, 91-100, https://doi.org/10.1680/ensu.2009.162.2.91.

Hughes, P. N., Glendinning, S., Mendes, J., Parkin, G., Toll, D. G., Gallipoli, D. \& Miller, P. E. (2009). Full-scale testing to assess climate effects on embankments. Proc. Instn Civ. Engrs - Engng Sustain. 162, No. 2, 67-79, https://doi.org/10.1680/ensu.2009. 162.2.67.

Jommi, C. (2000). Remarks on the constitutive modelling of unsaturated soils. In Experimental evidence and theoretical approaches in unsaturated soils (eds A. Tarantino and C. Mancuso), pp. 139-153. Rotterdam, the Netherlands: Balkema (Taylor \& Francis Group).

Kovacevic, N., Hight, D. W. \& Potts, D. M. (2007). Predicting the stand-up time of temporary London clay slopes at Terminal 5 , Heathrow Airport. Géotechnique 57, No. 1, 63-74, https://doi. org/10.1680/geot.2007.57.1.63.

Kovacevic, N., Hight, D. W., Potts, D. M. \& Carter, I. C. (2013). Finite-element analysis of the failure and reconstruction of the main dam embankment at Abberton Reservoir, Essex, UK. Géotechnique 63, No. 9, 753-767, https:/doi.org/10.1680/geot. 12.P.066.

Leroueil, S. (2001). Natural slopes and cuts: movement and failure mechanisms. Géotechnique 51, No. 3, 197-243, https://doi.org/ 10.1680/geot.51.3.197.39365.

Liu, G., Toll, D. G., Kong, L. \& Asquith, J. D. (2020). Matric suction and volume characteristics of compacted clay soil under drying and wetting cycles. Geotech. Test. J. 43, No. 2, 20170310 , https://doi.org/10.1520/GTJ20170310.

Lowe, J. A., Bernie, D., Bett, P., Bricheno, L., Brown, S., Calvert, D., Clark, R., Eagle, K., Edwards, T., Fosser, G., Fung, F., Gohar, L., Good, P., Gregory, J., Harris, G., Howard, T., Kaye, N., Kendon, E., Krijnen, J., Maisey, P., McDonald, R., McInnes, R., McSweeney, C., Mitchell, J. F. B., Murphy, J., Palmer, M., Roberts, C., Rostron, J., Sexton, D., Thornton, H., Tinker, J., Tucker, S., Yamazaki, K. \& Belcher, S. (2018). UKCP18 Science overview report. Exeter, UK: Met Office.

Lupini, J. F., Skinner, A. E. \& Vaughan, P. R. (1981). The drained residual strength of cohesive soils. Géotechnique 31, No. 2, 181-213, https://doi.org/10.1680/geot.1981.31.2.181.

Mendes, J. (2011). Assessment of the impact of climate change on an instrumented embankment: an unsaturated soil mechanics approach. PhD thesis, Durham University, Durham, UK.

Mendes, J. \& Toll, D. G. (2016). Influence of initial water content on the mechanical behavior of unsaturated sandy clay soil. Int. J. Geomech. 16, No. 6, D4016005, https://doi.org/10.1061/ (asce)gm.1943-5622.0000594.

Mesri, G. \& Cepeda-Diaz, A. F. (1986). Residual shear strength of clays and shales. Géotechnique 36, No. 2, 269-274, https://doi. org/10.1680/geot.1986.36.2.269.

Meter Group (2019). Meter Group retired and discontinued product manuals. Pullman, WA, USA: Meter Group. See http://library. 
metergroup.com/RetiredandDiscontinued/Manuals/ (accessed 19/06/2019)

Ng, C. W. W., Zhan, L. T., Bao, C. G., Fredlund, D. G. \& Gong, B. W. (2003). Performance of an unsaturated expansive soil slope subjected to artificial rainfall infiltration. Géotechnique 53, No. 2, 143-157, https://doi.org/10.1680/geot. 53.2.143.37272.

Network Rail (2017). Annual expenditure 2016-17. Milton Keynes, UK: Network Rail.

Network Rail (2018). Annual expenditure 2017-18. Milton Keynes, UK: Network Rail.

Nugent, H. (2012). Train derails in Cumbria after landslide. The Guardian, 30 August. See https:/www.theguardian.com/ uk/2012/aug/30/train-derails-west-cumbria-landslide (accessed 25/01/2019)

Nyambayo, V. P., Potts, D. M. \& Addenbrooke, T. I. (2004). The influence of permeability on the stability of embankments experiencing seasonal cyclic pore water pressure changes. In Advances in geotechnical engineering - the Skempton conference (eds R. J. Jardine, D. M. Potts and K. G. Higgins), pp. 898-910. London, UK: Thomas Telford.

Potts, D. M., Kovacevic, N. \& Vaughan, P. R. (1997). Delayed collapse of cut slopes in stiff clay. Géotechnique 47, No. 5, 953-982, https://doi.org/10.1680/geot.1997.47.5.953.

Ridley, A., McGinnity, B. \& Vaughan, P. (2004). Role of pore water pressures in embankment stability. Proc. Instn Civ. Engrs Geotech. Engng 157, No. 4, 193-198, https://doi.org/10.1680/ geng.2004.157.4.193.

Rouainia, M., Davies, O., O’Brien, T. \& Glendinning, S. (2009). Numerical modelling of climate effects on slope stability. Proc. Insth Civ. Engrs - Engng Sustain. 162, No. 2, 81-89, https://doi.org/10.1680/ensu.2009.162.2.81.

Schrefler, B. (1984). The finite element method in soil consolidation (with applications to surface subsidence). $\mathrm{PhD}$ thesis, University College Swansea, Swansea, UK.

Skempton, A. W. (1964). Long-term stability of clay slopes. Géotechnique 14, No. 2, 77-102, https://doi.org/10.1680/geot. 1964.14.2.77.

Skempton, A. W. (1985). Residual strength of clays in landslides, folded strata and the laboratory. Géotechnique 35, No. 1, 3-18, https://doi.org/10.1680/geot.1985.35.1.3.

Stirling, R. A., Hughes, P., Davie, C. T. \& Glendinning, S. (2015). Tensile behaviour of unsaturated compacted clay soils - a direct assessment method. Appl. Clay Sci. 112-113, 123-133, https://doi.org/10.1016/j.clay.2015.04.011.

Stirling, R., Helm, P., Glendinning, S., Asquith, J., Hughes, P. \& Toll, D. (2017). Deterioration of geotechnical infrastructure: the influence of asset aging through environmental cycling. In Proceedings of the 19th international conference on soil mechanics and geotechnical engineering (eds W. Lee, J.-S. Lee, H.-K. Kim and D.-S. Kim), pp. 3199-3202. London, UK: International Society for Soil Mechanics and Geotechnical Engineering.

Take, W. A. \& Bolton, M. D. (2011). Seasonal ratcheting and softening in clay slopes, leading to first-time failure. Géotechnique 61, No. 9, 757-769, https://doi.org/10.1680/geot. 9.P.125.

Tang, C. S., Cui, Y. J., Shi, B., Tang, A. M. \& Liu, C. (2011). Desiccation and cracking behaviour of clay layer from slurry state under wetting-drying cycles. Geoderma 166, No. 1, 111-118, https://doi.org/10.1016/j.geoderma.2011.07.018.

Toll, D. G., Lourenço, S. D. N. \& Mendes, J. (2013). Advances in suction measurements using high suction tensiometers. Engng Geol. 165, 29-37, https://doi.org/10.1016/j.enggeo.2012. 04.013.

Toll, D., Asquith, J., Fraser, A., Hassan, A., Liu, G., Lourenço, S., Mendes, J., Noguchi, T., Osinski, P. \& Stirling, R. (2015). Tensiometer techniques for determining soil water retention curves. In Proceedings of the 6th Asia-Pacific conference on unsaturated soil (eds Z. H. Chen, C. F. Wei, D. Sun and Y. Xu), pp. 15-22. Leiden, the Netherlands: CRC Press/Balkema.

Tsiampousi, A., Zdravkovic, L. \& Potts, D. M. (2017). Numerical study of the effect of soil-atmosphere interaction on the stability and serviceability of cut slopes in London clay. Can. Geotech. J. 54, No. 3, 405-418, https://doi.org/10.1139/cgj-2016-0319.

van Genuchten, M. T. (1980). A closed-form equation for predicting the hydraulic conductivity of unsaturated soils. Soil Sci. Soc. Am. J. 44, No. 5, 892-898.

Vaughan, P. R. \& Walbancke, H. J. (1973). Pore pressure changes and the delayed failure of cutting slopes in overconsolidated clay. Géotechnique 23, No. 4, 531-539, https://doi.org/10.1680/geot. 1973.23.4.531.

Wang, C., Zhang, Z., Liu, Y. \& Fan, S. (2017). Geometric and fractal analysis of dynamic cracking patterns subjected to wetting-drying cycles. Soil Till. Res. 170, 1-13, https://doi.org/ 10.1016/j.still.2017.02.005. 